\title{
The Study on Assets Check in Advanced University Bitao Zhang ${ }^{1, a}$, Fahai $\mathrm{Li}^{2, \mathrm{~b}}$
}

${ }^{1}$ Financial Department, Hubei University of Automotive Technology, Shiyan, China ${ }^{2}$ School of Electrical and Information Engineering, Hubei University of Automotive Technology, Shiyan, China

aqydzsw@163.com, bylfh73@163.com

\begin{abstract}
With the rapid development of Universities running mode, the scale of fixed assets is growing increasingly and the assets become more complex and difficult day after day. Thus the management becomes harder and harder. How to analyze the problems during capital management in a new situation and solve the current problem in assets and capital verification, is worthy of our study. In this paper, we illustrate the assets management mode from a financial point of view combining assets and capital verification issues in Hubei University of Automotive Technology.
\end{abstract}

Keywords: University, Liquidation, Assets check.

\author{
高校清产核资问题的研究 \\ 张必桃 ${ }^{1, a}$, 李发海 ${ }^{2, b}$ \\ $1^{1}$ 湖北汽车工业学院财务处, 十堰, 中国 \\ 2湖北汽车工业学院电气与信息工程学院, 十堰, 中国 \\ aqydzsw@163.com, bsylfh73@163.com
}

中文摘要. 随着高校办学模式快速发展, 拥 有固定资产的规模越来越大且构成日益复 杂, 管理难度逐渐增大, 如何在新形势下正 确认识资产管理中存在的问题, 解决清产核 资所面临的难题, 是值得我们研究的。本文 结合湖北汽车工业学院清产核资问题, 从实 际出发, 阐述了从财务角度来说明资产的管 理模式。

\section{关键词: 高校; 清产; 核资}

\section{1. 引言}

行政事业单位国有资产是国家政权建 设不可缺少的物质基础, 它们分布在行政管 理、公检司法、科研教育、文化卫生和部队 等各个系统[1], 而这些系统是各级政府保 证国家机器正常运转的不可缺少的职能部 门, 担负着社会管理、社会进步和国家安全 等繁重的社会任务。如何管好, 用好这些资 产, 维护资产所有者和使用者的合法权益, 促进资产合理、有效使用, 保障资产的完整 和不受侵犯, 对国家政权的建设和深化经济 体制改革都有着十分重要的意义。 
长期以来, 行政事业单位由于其自身的 特殊情况, 在国有资产管理方面存在一定程 度的滞后现象。除了国有资产流失现象外, 还存在国有资产的各种损失, 如: 盘亏、报 废、毁损造成的损失以及国有资产低效率运 营造成的损失等。

因此, 规范事业单位国有资产管理, 维 护国有资产的安全和完整, 合理配置国有资 产，提高国有资产使用效益[2]，是保证国 家行政机关履行职责和促进各项事业发展 的重要前提。文本结合实际情况, 对湖北汽 车工业学院的清产核资问题, 提出相关的管 理建议。

\section{2. 正确认识固定资产管理中存在的问题}

由于学院是2006年12月从东风公司脱 离出来的一所高等院校, 随着学院办学模式 快速发展, 拥有的固定资产的规模越来越大 且构成日益复杂, 管理难度逐渐增大, 目前 学院的固定资产总值已达 5 个多亿, 在全省 同类学校中处于前列。在新情况和新问题的 冲击下, 使得学院固定资产管理存在的问题 和薄弱环节凸显, 如管理意识淡薄, 账实不 符, 权责不明确等。主要表现在以下几个方 面:

(1) 对固定资产管理的认识不足, 管理 过程存在不规范现象。长期以来, 人们在思 想上普遍存在着 “重钱轻物, 重供轻管” 的 问题, 没有充分认识到加强固定资产管理实 际上是对资金使用效益的延续, 我校的固定 资产管理存在 “失之以软”、“失之以宽” 的问题。如资产购建以各部门为主, “谁购 建谁拥有, 谁拥有谁使用” 的现状形成了资 产名义上是学校所有, 实际上是使用部门所 有的管理体制。在这种管理体制下, 由于资 产管理与资产使用部门间的责任不明确, 未 能有效共享信息, 以致管理不到位, 造成资 源的浪费和管理效率低下等问题。

（2）固定资产管理制度不完善，管理方 法和手段滞后。主要反映在采购、验收、入 库缺乏严格规范的审批程序和监管制度。一 是购置资产缺乏计划性, 临时购置比较平 繁; 二是采购物资的程序缺乏规范性, 存在 谁使用谁申请谁采购的问题; 三是资产的验 收、入库、出库手续不健全, 各部门购置的
物品直按放置使用部门后再验收做帐入帐 的情况比较突出; 四是资产管理缺乏有效的 协调、监督和控制; 五是管理手段依旧停留 在手工登记和监管资产上, 数据有陈旧和静 态的特征, 不能及时反映资产的存量分布和 动态变化。

（3）固定资产管理机构分散[3]，职能不 清。固定资产管理是对属于学校的固定资产 进行组织、协调、监督和控制等的一系列活 动。学校没有设立专门的固定资产管理机构 前各类固定资产分散到各使用部门管理, 从 表面上看，资产管理涉及每一个部门，财务 部门负责资金核算，代表学校行使管理职 责。但在实际工作中, 由于分块管理, 缺乏 密切配合, 致使学院对各职能部门固定资产 的管理缺乏有效的协调、检查、监督和控制。

（4）产权不明晰，责任主体缺位。资产 使用部门责任意识不强。对固定资产管理缺 乏责任感, 固定资产损坏、丢失等现象较为 严重。

上述问题的存在, 严重制约和阻碍了我 校固定资产管理工作的健康有序发展, 必须 要下大力气, 全面改革传统管理模式, 创新 管理体制[4], 推动我校固定资产管理工作 上新台阶。

\section{3. 运用现代化手段实现固定资产的精细化 和动态化管理}

在十二五期间, 我校要在稳定规模的同 时, 积极将工作重心由外延发展转向内涵发 展。对此, 我们的资产管理工作也要有充分 准备, 必须用科学的发展观作指导, 进一步 转变思想观念, 拓展工作和研究领域, 资产 管理工作要有新思路, 要有新措施, 努力提 高服务和工作水平，在巩固成果基础上，推 动资产管理工作进一步走向科学化和精细 化。为此, 我认为, 资产管理应从以下几个 方面着手做好工作:

(1) 充分认识使用《高校固定资产管理 系统》的重要意义。《系统》借助校园网, 沟通、协调校内各职能部门、使用部门和使 用者按系统设定的权限和程序规范地履行 职责, 进行对固定资产验收、入库、建帐、 设卡、分布、借用、清查、处置、统计、报 表等各项管理活动, 从而实现对固定资产的 
全息、实时与多维监管, 纠正资产管理方面 的不正确认识, 彻底解决清查、统计、对帐 等关键时刻遇到的一些难题。《系统》的推 广使用, 对优化学院教育资源配置, 提高资 产利用率, 合理安排预算, 提升学院总体管 理水平有着十分重要的意义。

（2）加强领导, 强化措施, 确保《高校 固定资产管理系统》在我校的建立和运行。 运用现代信息技术管理学院固定资产工作, 涉及面广、技术性强、时间紧、任务重。学 院各部门必须齐心协力, 相互配合, 并从多 方面采取措施, 做好应用《系统》的保障工 作。

1) 加强领导, 明确分工。一是按照 “统 一领导, 归口管理, 分级负责, 责任到人” 的要求, 由学校固定资产管理领导小组统一 组织领导，资产管理处负责组织具体工作， 各单位各部门要积极参与配合, 专兼职资产 管理员要具体负责操作; 二是明确归口管理 部门的职责, 资产处负责固定资产监督验 收、审核、变动、处置、财产清查等日常管 理; 财务处根据经费使用情况, 对发票、验 收单等报帐审核; 三是各有关单位要明确固 定资产负责人、确定专职或兼职管理人员, 将管理责任落实到具体人, 切实做到人员落 实、工作落实。

2) 按照国家和省市的有关规定, 建立 健全固定资产各项规章制度, 明确资产从购 置、使用、管理、清理到处置各个环节的运 行程序和审批程序, 确保有章可循。

3）根据运用现代信息技术管理固定资 产工作的需要和现有条件, 安排必要的运行 经费, 保证管理系统运行的基本条件。

4）按照职责分工和岗位责任制要求, 定期对运用现代信息技术管理固定资产工 作人员进行综合考核, 奖优罚劣, 充分调动 工作人员爱岗敬业、当家理财的积极性。

(3) 要树立科学的管理理念, 始终坚持 以人为本的思想, 坚持以服务师生为宗旨优 化配置资源。在管理方式上, 要由对物的管 理转变到对人的管理上来, 真正由“要我管” 转变到 “我要管” 上来。要在管理活动中始 终坚持效益优先的理念, 要坚持 “向管理要 资源”、“向管理要效益”，把充分发挥固 定资产在教学、科研和行政运行中的使用效
益作为资产管理工作的出发点和落脚点。要 进一步优化资源配置, 坚持勤俭办学, 不搞 形象工程, 不搞豪华设施, 坚持科学决策, 避免投资浪费, 切实将有限的资源配置到教 育教学活动上来, 切实降低办学成本, 减少 浪费。要通过资源的合理配置, 提升学校的 核心竞争力和持续发展能力。

（4）进一步规范和完善资产管理的组织 体系、制度体系。坚持管理创新、制度创新 和机制创新, 使我校资产管理工作与学院向 内涵发展转变相适应。根据现代大学管理的 要求, 进一步理顺管理体制, 通过进一步明 确职责权限关系, 建立顺畅的资产管理运行 机制。一是高度重视制度建设; 二是加强固 定资产的源头管理; 三是建立固定资产对外 投资、出租、出借和担保等事项审批责任制, 加强收益管理; 四是进一步完善学校内部控 制制度，落实管理规范，积极推行民主决策 机制。

（5）建设一支政治思想过硬、基础扎实、 业务熟练、作风严谨、高素质、高效率的资 产管理队伍。加强资产管理不仅是高等教育 事业发展的需要，也是高校自身发展和改革 的需要。学院资产管理处要切实担负起组 织、协调、监督与管理的责任; 同时, 要建 设一支政治思想过硬、基础扎实、业务熟练、 作风严谨、高素质、高效率的资产管理队伍, 有目的、有计划、有步骤地组织资产管理人 员进行培训，不断提高资产管理人员的政策 水平、业务能力, 充分调动资产管理人员爱 岗敬业、当家理财的积极性, 为推进学院资 产管理深化改革, 提高学院的整体管理水平 奠定基础[5]。

\section{4. 湖北汽车工业学院固定资产管理建议}

湖北衡平资产评估有限公司接受委托, 对我校2013年度资产清查表进行了专项核 查, 在审核过程中, 了解了我校内部控制中 有关会计制度、会计工作机构和人员职责、 财产管理制度、内部审计制度等有关方面的 情况, 并作了分析研究。该评估公司认为, 我校现有的内部控制总体上还有较好的, 但 有的方面还存在一些较薄弱之处。 


\section{1 存货管理}

我校存在未按照财务制度的要求定期 对存货进行盘点。

针对上述情况，湖北衡平公司建议:

(1) 完善实物资产管理的岗位责任制度, 加强对实物资产的验收入库、领用、发出、 盘点、保管及处置等关键环节的控制;

（2）完善存货管理的内控制度, 定期对 存货进行盘点, 年末对存货进行全面盘点, 由部门负责人、财务人员、保管人员组成存 货盘点小组, 并及时查找存货盘点差异原 因; 盘点范围应为包括账外实物资产在内的 所有实物资产, 盘点内容除实物数量外还应 包括: 资产可使用状况, 资产存放地点或使 用人等, 并形成书面盘点记录; 明确盘点记 录作为会计原始凭证归档, 明确相关人员对 实物资产的责任;

（3）加强资产部门与院系及管理部门的 联系, 便于财务部门及时进行存货流转的账 务处理, 并对盘亏、毁损、变质、转移的存 货及时进行账务处理。

\section{2 固定资产管理}

在清查中, 湖北衡平公司发现财务账与 资产账有不符的现象。

针对上述情况, 湖北衡平公司建议:

（1）实行 “三定”管理, 即: 定位置、 定数量、定责任。定位置, 主要按部门配备 的办公设备, 原则上不随人员变动而变动。 定数量, 是指财产管理人员按照部门建立明 细账, 确定各部门的实物数量、金额。定责 任, 是指各部门负责人要负责本部的实物管 理, 维护、保养、不丢失、不损坏。

（2）实物责任到人，使每件资产有专人 管理, 造成丢失和损失要给责任人必要的行 政和经济处罚, 违纪违法的要依法处理。

（3）定期清查盘点, 相关部门每年对实 物进行盘点, 发现情况要及时处理, 做到实 物和账面相符, 凡属于资产增减一律计入明 细账和总账。购置、报损、报废、调入调出 要与财务部门核对, 两账记载数量金额相 符, 切实做到账账相符、账实相符。

\section{5. 结束语}

本文结合湖北汽车工业学院清产核资 问题, 从实际出发, 阐述了从财务角度来说 明资产的管理模式。实践证明, 运用现代化 手段实现固定资产的精细化和动态化管理, 是高校资产管理的首选。另一方面, 能保障 国有资产的安全和完整优化国有资产的配 置, 提高国有资产的使用效益, 防止国有资 产流失。

\section{References}

[1] J. C. QIU, On the Management of State-owned Assets in Institutions of Higher Education Viewed from Asset and Capital Verification, Journal of Sichuan University of Science \& Engineering (Social Sciences Edition), vol. 21, pp. 77-81, 2006.

[2] H. TIAN and J. J. TUO, Approaches to Management of University State- owned Assets, Journal of Inner Mongolia University of Finance and Economics, vol. 13, pp. 79-81, 2015.

[3] J. ZH. LIU, Stand for the assets and strengthen the management of fixed assets, Journal of Wuyi University, vol. 28, pp. 99-102, 2009.

[4] Y. X. Du, Through inspection of fixed assets to approach new management ideas of university fixed assets of teaching and researching equipments, China Modern Educational Equipment, vol. 16, pp. 17-19, 2014.

[5] X. CH. Hou and G. B. LU, Discussion on the management of instruments and equipment through assets accounting in colleges and universities, Experimental Technology and Management, vol. 27, pp. 203-205, 2010. 